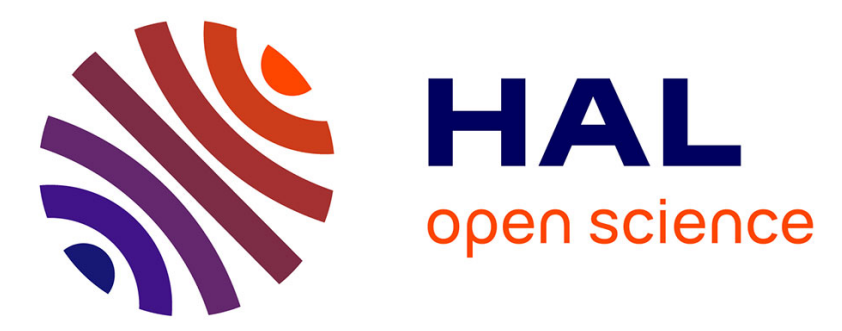

\title{
Better Implant Positioning and Clinical Outcomes With a Morphometric Unicompartmental Knee Arthroplasty. Results of a Retrospective, Matched-Controlled Study
} Jean-Charles Escudier, Christophe Jacquet, Xavier Flecher, Sebastien Parratte, Matthieu Ollivier, Jean-Noël Argenson

\section{To cite this version:}

Jean-Charles Escudier, Christophe Jacquet, Xavier Flecher, Sebastien Parratte, Matthieu Ollivier, et al.. Better Implant Positioning and Clinical Outcomes With a Morphometric Unicompartmental Knee Arthroplasty. Results of a Retrospective, Matched-Controlled Study. The Journal of Arthroplasty, 2019, 34 (12), pp.2903-2908. 10.1016/j.arth.2019.07.031 . hal-02528244

HAL Id: hal-02528244

https://hal.science/hal-02528244

Submitted on 13 Apr 2020

HAL is a multi-disciplinary open access archive for the deposit and dissemination of scientific research documents, whether they are published or not. The documents may come from teaching and research institutions in France or abroad, or from public or private research centers.
L'archive ouverte pluridisciplinaire HAL, est destinée au dépôt et à la diffusion de documents scientifiques de niveau recherche, publiés ou non, émanant des établissements d'enseignement et de recherche français ou étrangers, des laboratoires publics ou privés. 


\title{
Better Implant Positioning and Clinical Outcomes With a Morphometric Unicompartmental Knee Arthroplasty. Results of a Retrospective, Matched-Controlled Study
}

\author{
Jean-Charles Escudier, MD ${ }^{\text {a, b }}$, Christophe Jacquet, $\mathrm{MD}^{\mathrm{b}}$, Xavier Flecher, $\mathrm{MD}, \mathrm{PhD}^{\mathrm{a}}{ }^{\mathrm{b}}$, \\ Sebastien Parratte, MD, PhD ${ }^{\text {a, b }}$, Matthieu Ollivier, MD, $\mathrm{PhD}^{\mathrm{a}, \mathrm{b}}$, \\ Jean-Noel Argenson, MD, PhD a, b, * \\ ${ }^{a}$ Department of Orthopaedic Surgery, APHM, Institut du Mouvement et de l'appareil Locomoteur, Sainte-Marguerite Hospital, Marseille, France \\ ${ }^{\mathrm{b}}$ Aix-Marseille University, CNRS, Marseille, France
}

\section{Keywords:}

unicompartmental knee arthroplasty

morphometric tibial tray

implant positioning

medial overhang

tibial bone coverage

\begin{abstract}
A B S T R A C T
Background: During medial unicompartmental knee arthroplasty (UKA), tibial tray implantation requires compromise between bone coverage and rotational position. It was hypothesized that morphometric tibial tray (MTT) would improve implant positioning and subsequently clinical outcomes as compared to symmetric tibial tray (STT).

Methods: A total of 106 patients who underwent medial UKA in our department between January 2017 and March 2018 were included matched on gender and age (53 in each group). Inclusion criteria were symptomatic medial femorotibial osteoarthritis, functional anterior cruciate ligament, primary arthritis, or osteonecrosis. Rotation of the tibial implant, tibial bone coverage, medial and posterior overhang were assessed with a postoperative computed tomography scan. The Knee Society Score (KSS), the Knee injury and Osteoarthritis Outcome Score Short Form (KOOS SF), and the quality of life score EuroQoL 5Dimensions 3-Levels (EQ5D3L) were assessed at a minimum of 1-year follow-up.

Results: Implants of the STT group exhibited more external rotation $\left(6.3^{\circ} \pm 4.02^{\circ}\right.$ vs $\left.4.6^{\circ} \pm 3.59^{\circ} ; P=.04\right)$, and medial and posterior overhang $>3 \mathrm{~mm}(35 \%$ vs $0 \%$ and $22 \%$ vs $0 \% ; P<.0001)$ but no difference for tibial bone coverage $(97.3 \% \pm 11.35 \%$ vs $94.7 \% \pm 10.89 \% ; P=.23)$. Global KSS (188.6 \pm 6.6 vs $175.2 \pm 31.7 ; P$ $<.01)$, KOOS SF $(16.9 \pm 6.1$ vs $22.5 \pm 11.8 ; P<.003)$, and EQ5D3L $(1 \pm 0.1$ vs $0.9 \pm 0.2 ; P<.001)$ were higher in MTT group. According to the multivariate analysis, MTT had a positive independent effect on the KSS, KOOS SF, and EQ5D3L.

Conclusion: The use of an MTT in medial UKA allowed better implant positioning when decreasing the rate of overhang; superior short-term clinical outcomes were found as compared to STT.
\end{abstract}

Unicompartmental knee arthroplasty (UKA) is an effective treatment for single-compartment osteoarthritis [1-3]. Several studies reported excellent 10-year survivorship of UKA [4-7] with

Investigation was performed at the Institute for Locomotion, St. Marguerite Hospital, Aix-Marseille University, Marseille, France.

One or more of the authors of this paper have disclosed potential or pertinent conflicts of interest, which may include receipt of payment, either direct or indirect, institutional support, or association with an entity in the biomedical field which may be perceived to have potential conflict of interest with this work. For full disclosure statements refer to https://doi.org/10.1016/j.arth.2019.07.031.

* Reprint requests: Jean-Noel Argenson, MD, PhD, Aix-Marseille University, CNRS, ISM UMR 7287, 13009 Marseille, France. better physiological function, quicker recovery, and less perioperative complications as compared to total knee arthroplasty (TKA) [8-10]. UKA remains however a demanding surgical procedure, and optimal implant positioning is essential to obtain satisfactory outcomes [11,12]. The fit of the tibial component has been shown to have an important impact on the success of UKA procedures [13]: implant overhang can lead to soft tissue impingement and pain (particularly with the medial collateral ligament [MCL]) [14,15]. Conversely, tibial tray subsidence and early loosening are increased when cortical support is insufficient and tibial surface undercovered [16,17]. Furthermore, coronal plane position error may lead to abnormal contact stress and MCL tension [18]. Historical UKA designs did not aim at reproducing tibial plateau morphometry [19] but were rather built as simple symmetric shape. Consecutively, 
compromises in size and rotation positioning might have to be realized intraoperatively $[18,20]$. Following the good results obtained in TKA with morphometric and lateralized tibial implants, new tibial trays for UKA have been developed. The rational of these implants is to optimize the rotational-coverage ratio, maximizing the cortical support while limiting the potential conflicts with the soft tissues. It was our hypothesis that the use of a morphometric tibial component in UKA can improve in vivo the positioning of the tibial tray and consequently the clinical results at a minimum of 1 -year follow-up. Therefore, we aimed at comparing the results of 2 different tibial trays considering (1) radiological results (bone coverage, rotation of tibial implant, medial overhang, and posterior overhang) as measured on a postoperative computed tomography (CT) scan using a validated method, (2) clinical results as measured at a minimum 1-year follow-up using validated scores (Knee Society Score [KSS], Knee injury and Osteoarthritis Outcome Score Short Form [KOOS SF], EuroQoL 5-Dimensions 3-Levels [EQ5D3L]), and (3) clinical outcomes between the subgroups with or without medial or posterior overhang.

\section{Methods}

\section{Patients}

After gaining local ethics committee approval, a retrospective comparative study identified 151 patients who underwent medial UKA in our department between January 2017 and March 2018. Of these patients, 57 received a morphometric tibial tray (MTT) UKA (Persona Partial Knee; Zimmer-Biomet, Warsaw, IN) and 94 a symmetric tibial tray (STT) UKA (ZUK; LimaCorporate, Udine, Italy).

Inclusion criteria were symptomatic medial femorotibial osteoarthritis, functional anterior cruciate ligament, primary arthritis or osteonecrosis, failure of conservative treatment, minimal follow-up of 1 year, and all clinical and radiological data available. Exclusion criteria were knee sagittal instability, knee valgus or varus superior to $10^{\circ}$, post-traumatic knee osteoarthritis, history of surgery on the knee, and personal history of trauma, sepsis, tumor, and inflammatory or skeletal disease that could influence clinical outcomes.

For patients meeting both inclusion and no exclusion criteria, a matched pair process identified 53 patients in the MTT group and selected 53 patients from the STT (matching criterion was age $[ \pm 5$ years] and gender).

The 2 groups were comparable in terms of demographic and preoperative parameters (Tables 1 and 2).

\section{Procedure}

Two cemented medial UKA (ZUK and Persona Partial Knee) were implanted: the symmetric group received an STT (ZUK) and the morphometric group received an MTT (Persona Partial Knee). All surgeries were performed by 3 senior surgeons of our institution using the same previously described technique [21]. The only differences between the procedures were the use of different ancillaries and implants.

Table 1

Intraobserver and Interobserver Reliability by Variable.

\begin{tabular}{lcl}
\hline Variable & Intraobserver & Interobserver \\
\hline Rotation of tibial implant & $0.86(0.65-0.95)$ & $0.84(0.63-0.92)$ \\
Tibial bone coverage & $0.84(0.62-0.9)$ & $0.81(0.61-0.87)$ \\
Medial overhang & $0.99(0.99-1)$ & $0.96(0.94-0.98)$ \\
Posterior overhang & $0.9999(0.99-1)$ & $0.98(0.96-1)$ \\
\hline
\end{tabular}

Table 2

Preoperative Data.

\begin{tabular}{llll}
\hline Variables & Symmetric $(\mathrm{N}=53)$ & Morphometric $(\mathrm{N}=53)$ & $P$ \\
\hline Sex ratio (female/male) & $17 / 36$ & $17 / 36$ & - \\
Age $(\mathrm{y})$ & $65(42-79)$ & $68(48-83)$ & .07 \\
BMI $\left(\mathrm{kg} / \mathrm{m}^{2}\right)$ & $27.4(21-37)$ & $27.1(18-38)$ & .72 \\
Side $($ right $/ \mathrm{left})$ & $24 / 29$ & $25 / 28$ & .96 \\
Flexion $\left({ }^{\circ}\right)$ & $104(60-125)$ & $103(75-125)$ & .48 \\
KSS & & & \\
Pain & $19 \pm 2$ & $14 \pm 1.7$ & .14 \\
Knee & $52 \pm 2$ & $50 \pm 2$ & .40 \\
Function & $73 \pm 3$ & $70 \pm 3$ & .53 \\
Global & $122 \pm 5$ & $118 \pm 5$ & .58 \\
KOOS SF & $33 \pm 2$ & $38 \pm 2$ & .09 \\
EQ5D3L & $0.4 \pm 0.1$ & $0.4 \pm 0$ & .49 \\
HKA $\left(^{\circ}\right)$ & $176 \pm 1$ & $175 \pm 1$ & .13 \\
\hline
\end{tabular}

BMI, body mass index; KSS, Knee Society Score; KOOS SF, Knee injury and Osteoarthritis Outcome Score Short Form; EQ5D3L, EuroQoL 5-Dimensions 3-Levels; HKA hip-knee-ankle angle.

The same perioperative protocol (pain and blood management) and postoperative regiment were used in both groups.

\section{Radiological Results}

A submillimetric CT scan with protocol of attenuation of metal artifacts was performed 3 months after surgery for all the patients. Images were analyzed using imaging Aw Server 4.2 (GE Medical Systems, LLC) to calculate the following parameters:

- Rotation of the tibial implant: rotation of the tibial implant was defined by the angle between the anteroposterior axis of the tibial implant and the anteroposterior axis of the tibial plateau, as described by Servien et al [22]. The anteroposterior axis of the tibial implant was defined as the line passing through the external edge of the tibial implant. The anteroposterior axis to the tibial plateau was defined as the perpendicular line to the tangent of the plateau tibial posterior cortical, as described by Yoshioka et al [23] (Fig. 1).

- Tibial bone coverage (TBC): TBC was measured by subtracting the tibial implant surface from the surface of the tibial cut, as described by Servien et al [24]. The surface of the tibial cut was defined as the section immediately below the tibial implant. The surface of the tibial implant was defined as the section passing through the thickness of the tibial tray (Fig. 2). A result less than $100 \%$ corresponded to a non-overflowing implant and a result greater than $100 \%$ to an overflowing implant.

- Medial overhang: distance in millimeters between the medial edge of the tibial component and the medial most border of the proximal tibia directly underneath the implant, as measured by Bizzozero et al [25].

- Posterior overhang: distance in millimeters between the posterior edge of the tibial component tray and the posterior most border of the proximal tibia directly underneath the implant (Fig. 3).

A positive value was attributed to an overlapping implant, and a negative value to an implant within the tibial plateau. A value greater than $+3 \mathrm{~mm}$ was considered as a significant overhang [15].

The tomodensitometric measures were realized by 2 independent nonoperator examiners. To analyze the interobserver and intraobserver reproducibility of the measurements, the intraclass and interclass correlation coefficients were calculated for each analysis. They were greater than 0.8 for each measure (rotation, coverage, medial and posterior overhang), demonstrating a good intraobserver and interobserver reproducibility (Tables 1 and 2). 

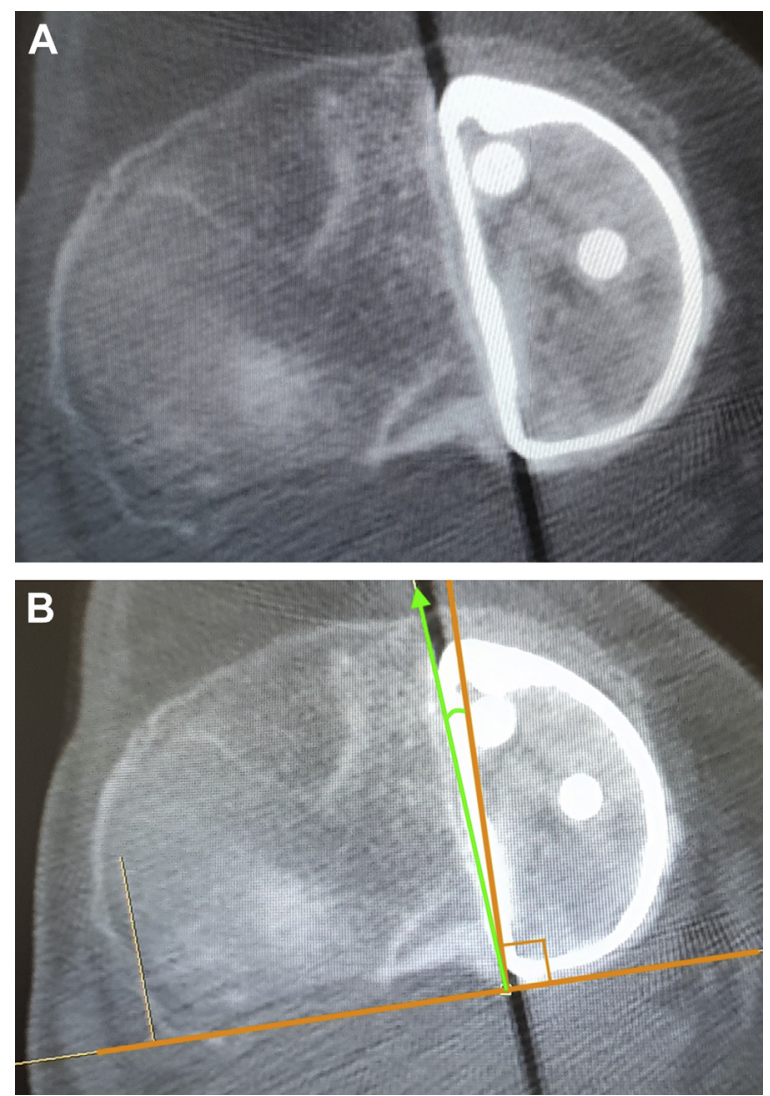

Fig. 1. Calculation of the tibial implant rotation: (A) Surimposition of the cut passing through the implant and the cut below the implant. (B) Axis of the tibial implant (green arrow); perpendicular line to the tangent of the tibia plateau posterior cortex (orange line).

\section{Clinical Results}

Clinical follow-up was completed at 3 months, 1 year, and every year thereafter. Clinical outcomes were measured using the KSS [26], the KOOS SF [27], and the quality life score EQ5D3L.

\section{Statistics}

Before initiation of the study, a sample size analysis was done to estimate the number of patients necessary to obtain an $80 \%$ statistical power. Fifty patients by groups were needed to distinguish difference in terms of tibial tray coronal positioning $>3^{\circ} \pm 2^{\circ}$ between group (defined as minimal clinically important difference [MCID]). A post hoc analysis also confirmed that with 50 patients by group, we were able to evaluate difference between group superior to the published MCID of the KOOS (8 to 10 points [28]). Data were represented as mean values with ranges. Chi-squares tests were used to compare binary variables (demographic data) in the 2 groups. To compare the value of rotation, coverage, and overhang, the Student $t$-test was used. To compare functional outcomes (maximal flexion of the knee, KSS, KOOS SF, EQ5D3L), the Student $t$-test was used. Wilcoxon test was used to compare the clinical outcomes between the subgroups with or without medial or posterior overhang. Multiple linear regression was used for multivariate analysis to determine the relationship between the clinical outcomes (KSS, KOOS SF, EQ5D3L) and any other variable that could influence the outcome (gender, age, body mass index, side, implant used, rotation of the tibial implant, medial or posterior overhang $>3$ $\mathrm{mm}$ ). Regarding our primary outcome with our available simple size and postoperative score standard deviation, this study had $80 \%$ power to detect a difference $>10$ points on the KSS with a $P<.05$ level. Statistical analyses were performed with use of SSPS software (IBM, Armonk, NY).

\section{Results}

\section{Radiological Results}

Tibial implants were positioned with a mean external rotation of $6.3^{\circ} \pm 4.02^{\circ}\left(-1^{\circ}\right.$ to $\left.15^{\circ}\right)$ in STT group vs $4.6^{\circ} \pm 3.59^{\circ}$ (range, $-3^{\circ}$ to $\left.12^{\circ}\right)$ in MTT group $(P=.04$ : but difference inferior to defined MCID). Regarding TBC, $97.3 \% \pm 11.4 \%$ (78.4\%-147.2\%) was covered in STT group vs $94.7 \% \pm 10.9 \%(73.3 \%-121 \%)$ in MTT group without statistical difference $(P=.23)$. Medial overhang was significantly higher in the STT group compared to the MTT group, $1.5 \pm 2.02 \mathrm{~mm}$ ( -1.9 to $4.9 \mathrm{~mm})$ vs $-0.3 \pm 1.84 \mathrm{~mm}(-2.5$ to $3.5 \mathrm{~mm})$, respectively $(P<.001)$. No difference was found for posterior overhang, $-0.5 \pm$ $3.61 \mathrm{~mm}(-3.61$ to $7.8 \mathrm{~mm})$ in the STT group vs $-1.6 \pm 2.10 \mathrm{~mm}$ $(-5.9$ to $2.8 \mathrm{~mm})$ in the MTT group. The rate of overhang was significantly higher in the STT group with $35 \%$ of STT positioned with a medial overhang $>3 \mathrm{~mm}$ and $22 \%$ with a posterior overhang $>3 \mathrm{~mm}$ vs $0 \%$ of medial and posterior overhang in the MTT group $(P<.0001)$. The radiological results are summarized in Table 3.

\section{Clinical Results}

At the last follow-up, all postoperative clinical scores were significantly improved in both groups compared to the preoperative scores (all $P<.05$ ). There were no complications such as early failure in the 2 groups. The postoperative scores were significantly
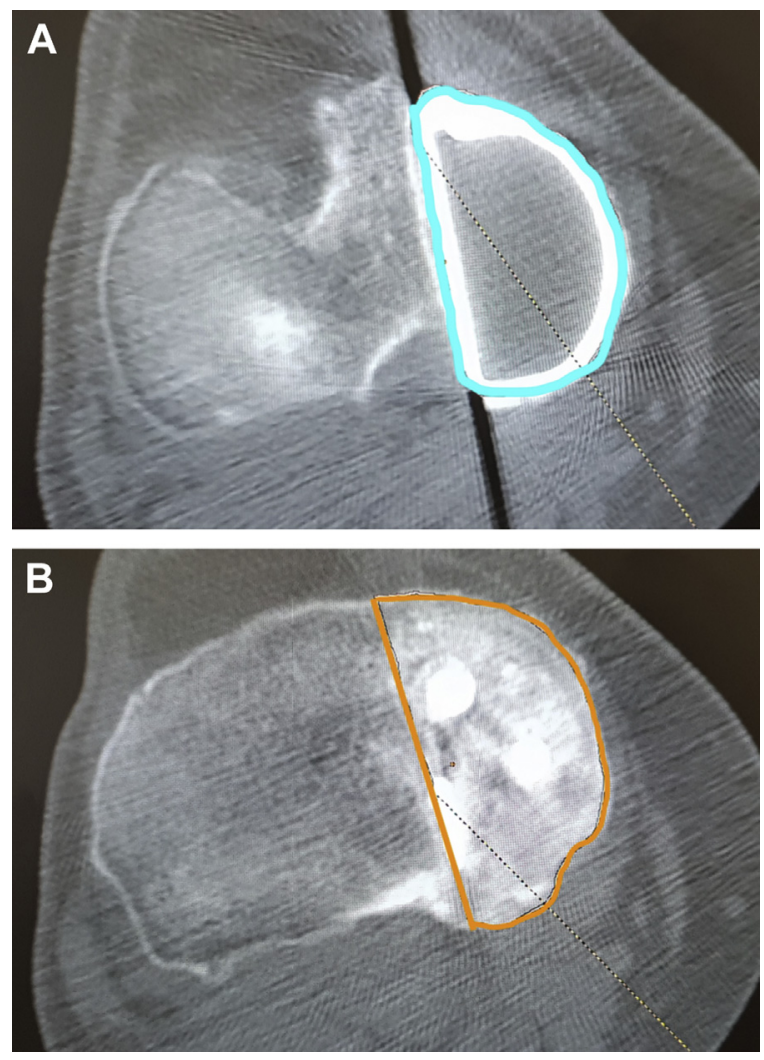

Fig. 2. Calculation of tibial bone coverage. (A) Tibial implant surface (blue). (B) Surface of the resected medial tibial plateau (section immediately below the tibial implant) (orange). 

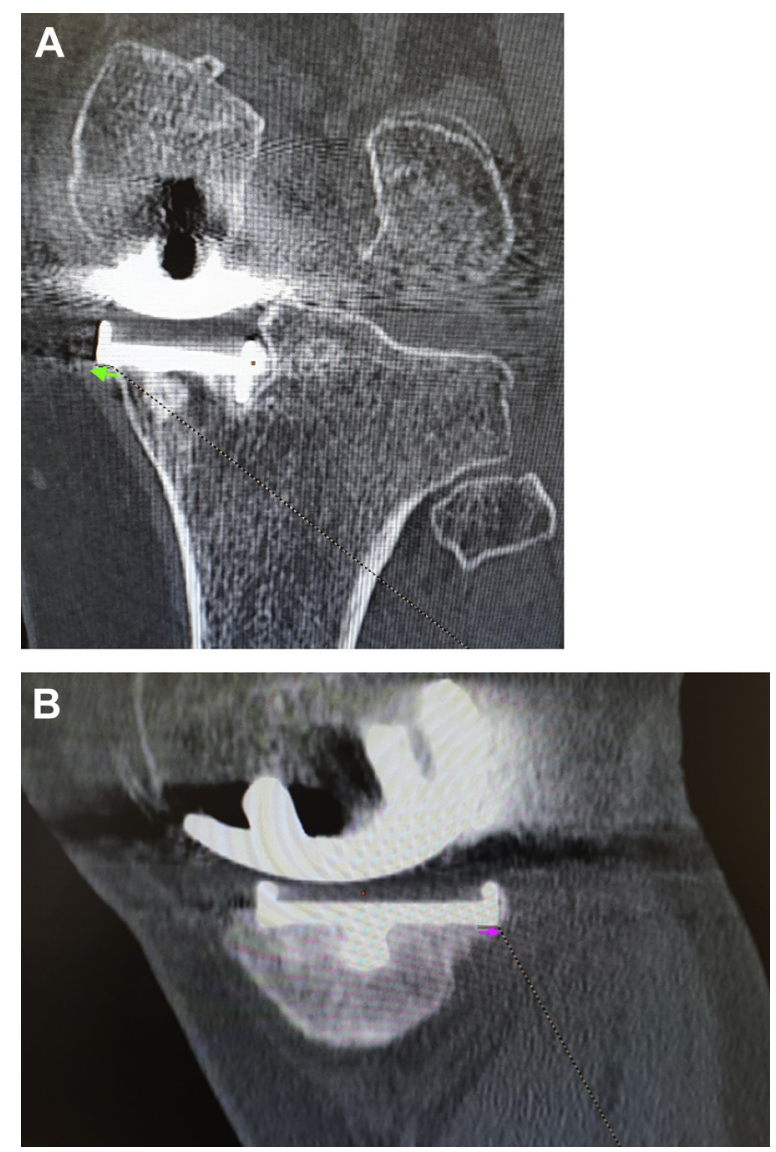

Fig. 3. Calculation of overhang. (A) Medial overhang (green arrow). (B) Posterior overhang (pink arrow).

higher in the MTT group for maximal flexion of the knee, KSS knee and pain component, and the KOOS $(P<.05)$. No difference was found for the EQ5D3L, the function subscore, and global KSS. The clinical results are summarized in Tables 4 and 5 . The improvement in maximal flexion of the knee was significantly higher in the overhang $<3-\mathrm{mm}$ subgroup compared to the overhang $>3-\mathrm{mm}$ subgroup $\left(13.9^{\circ} \pm 2.16^{\circ}\right.$ vs $\left.2.69^{\circ} \pm 4.82^{\circ} ; P=.037\right)$. No clinical difference was found between subgroups regarding posterior overhang $>3 \mathrm{~mm}$. After multivariate analysis, the use of the MTT had a positive effect on the pain component $(P=.017)$ and knee component $(P=.008)$ of the KSS, global KSS $(P=.043)$, KOOS SF $(P<.001)$, and the EQ5D3L $(P<.0001)$. Younger patients also exhibited higher $\operatorname{KOOS~SF}(P=.033)$.

Table 3

Postoperative Radiological Results.

\begin{tabular}{lccl}
\hline Variables & $\begin{array}{l}\text { Symmetric } \\
(\mathrm{N}=53)\end{array}$ & $\begin{array}{l}\text { Morphometric } \\
(\mathrm{N}=53)\end{array}$ & $P$ \\
\hline HKA & $176.4 \pm 1.69$ & $176.8 \pm 2.39$ & .72 \\
Rotation of tibial implant $\left(^{\circ}\right)$ & $6.3 \pm 4.02$ & $4.6 \pm 3.59$ & $.049^{\mathrm{a}}$ \\
Tibial bone coverage (\%) & $97.3 \pm 11.35$ & $94.7 \pm 10.89$ & .42 \\
Medial overhang & & & \\
$\quad$ Average (mm) & $1.5 \pm 2.02$ & $-0.3 \pm 1.84$ & $<.0001^{\mathrm{a}}$ \\
$\quad$ >3 mm (\%) & $35 \%$ & 0 & $<.0001^{\mathrm{a}}$ \\
$\begin{array}{l}\text { Posterior overhang } \\
\text { Average (mm) }\end{array}$ & $-0.5 \pm 3.61$ & $-1.6 \pm 2.10$ & .081 \\
$\quad>3$ mm & $22 \%$ & 0 & $.0015^{\mathrm{a}}$ \\
\hline
\end{tabular}

Values are mean \pm SD.

HKA, hip-knee-ankle angle; SD, standard deviation.

a Statistical difference.

\section{Discussion}

An optimally implanted UKA tibial component would be one that can flush with all edges of the tibia. This is often not possible, partly because current traditional tibial components may not be of ideal shape and often require a compromise between optimal rotation and bone coverage [18,20]. Fitzpatrick et al [19] and Servien et al [24] reported a better theoretical positioning with an optimized rotation-coverage ratio using a morphometric tibial implant in UKA. To our knowledge, no study evaluated in vivo the potential radiological and clinical benefits of this new design philosophy. We hypothesized that the use of a morphometric tibial component in UKA can improve in vivo the positioning of the tibial tray and consequently the clinical results at a minimum of 1-year follow-up. The results of our study showed that the use of a new morphometric design for the tibial component enabled a better positioning in rotation with the same TBC without medial or posterior overhang.

Several limitations should be outlined in our study. There was no randomization or matching but the 2 groups were comparable for preoperative demographic, clinical, and radiological data. The relatively small size of each group (53 patients) can be balanced by the a priori calculation of the number of subjects needed to show a statistical difference for our primary outcome. The clinical results were evaluated at 1 year only, but the goal of this study was to analyze whether there was any correlation of the 1-year clinical results with the implant position and not to compare the raw clinical scores at a later follow-up. Despite those limitations, this study is the first in vivo radiological and clinical comparison between MTT and STT for UKA.

Few studies demonstrated in vitro the theoretical advantages of morphometric tibial implant in UKA. Fitzpatrick et al [19] concluded on 34 tibiae that theoretical design provided significantly better cortical rim coverage than commercially available implants regardless of shape: $79.2 \%$ of cortical bone coverage as opposed to $74 \%$ and $52 \%$ for teardrop and D-shaped implants, respectively. Carpenter et al [13] found that patient-specific implants provided significantly greater cortical rim surface area coverage compared to off-the-shelf implants: $77 \%$ vs $43 \%$ respectively when using morphometric data from 30 patients who undergo UKA. Compared to these studies, we found in vivo a better TBC for the 2 different implants (97\% for STT group and 95\% for MTT group) but no statistical difference between them. These studies only measured TBC and ignored the potential effect of the shape on the implant rotation or the overhang. In our study, tibial implants were positioned in a slight external rotation, $6.3^{\circ}$ for STT group vs $4.6^{\circ}$ for MTT group. Our results are in agreement with others studies: Servien et al [22] reported a mean tibial component external rotation of $6.5^{\circ} \pm 5.1^{\circ}\left(-6^{\circ}\right.$ to $\left.13.2^{\circ}\right)$ in medial UKA using CT scan in 19 knees. Iriberri and Aragon [29] found an

Table 4

Postoperative Clinical Results

\begin{tabular}{lccc}
\hline Variables & Symmetric $(\mathrm{N}=53)$ & Morphometric $(\mathrm{N}=53)$ & $P$ \\
\hline Flexion $\left(^{\circ}\right)$ & $117.1 \pm 8.2$ & $119.2 \pm 4.5$ & .134 \\
KSS & & & \\
Pain & $47.1 \pm 6$ & $48.7 \pm 2.4$ & .076 \\
Knee & $85.1 \pm 10.8$ & $91.2 \pm 4.3$ & $<.001^{\mathrm{a}}$ \\
Function & $94.0 \pm 9.2$ & $97.3 \pm 4.6$ & $.02^{\mathrm{a}}$ \\
Global & $175.2 \pm 31.7$ & $188.6 \pm 6.6$ & $<.01^{\mathrm{a}, \mathrm{b}}$ \\
KOOS SF & $22.5 \pm 11.8$ & $16.9 \pm 6.1$ & $.003^{\mathrm{a}}$ \\
EQ5D3L & $0.9 \pm 0.2$ & $1 \pm 0.1$ & $<.001^{\mathrm{a}}$ \\
\hline
\end{tabular}

KSS, Knee Society Score; KOOS SF, Knee injury and Osteoarthritis Outcome Score Short Form; EQ5D3L, EuroQoL 5-Dimensions 3-Levels.

a Statistical difference.

b Differences reaching published minimal clinically important differences. 
Table 5

Postoperative Improvement Outcomes.

\begin{tabular}{lclll}
\hline Variables & $\begin{array}{l}\text { Symmetric } \\
(\mathrm{N}=53)\end{array}$ & $\begin{array}{l}\text { Morphometric } P \\
(\mathrm{~N}=53)\end{array}$ & $\begin{array}{l}\text { Mean Difference }+ \\
95 \% \mathrm{CI}\end{array}$ \\
\hline Maximal flexion $\left(^{\circ}\right)$ & $8.9 \pm 2.4$ & $15.9 \pm 2.3$ & $.037^{\mathrm{a}}$ & $7.03(0.42$ to 13.63$)$ \\
KSS & & & & \\
$\quad$ Pain & $28.5 \pm 1.9$ & $33.9 \pm 1.8$ & $.043^{\mathrm{a}}$ & $6.23(0.19$ to 10.6$)$ \\
Knee & $32.6 \pm 2.6$ & $41.4 \pm 2.4$ & $.014^{\mathrm{a}}$ & $9.54(1.79$ to 15.81$)$ \\
Function & $21.4 \pm 3.3$ & $27.4 \pm 3.1$ & .194 & $5.95(-3.08$ to 14.97$)$ \\
$\quad$ Global & $57.3 \pm 5.79$ & $70.7 \pm 5.39$ & $.093^{\circ}$ & $13.4(2.331$ to 29.10$)$ \\
KOOS SF & $9.8 \pm 2.2$ & $21.0 \pm 2.0$ & $.0003^{\mathrm{a}, \mathrm{b}}$ & $11.2(5.28$ to 17.08$)$ \\
EQ5D3L & $0.47 \pm 0.04$ & $0.54 \pm 0.04$ & .13 & $0.08(0.04$ to 0.20$)$ \\
\hline
\end{tabular}

Values are mean $\pm \mathrm{SD}$.

KSS, Knee Society Score; KOOS SF, Knee injury and Osteoarthritis Outcome Score Short Form; EQ5D3L, EuroQoL 5-Dimensions 3-Levels; SD, standard deviation.

a Statistical difference.

b Differences reaching published minimal clinically important differences.

average angle of $11.9^{\circ}$ of external rotation $\left(-1^{\circ}\right.$ to $\left.32^{\circ}\right)$ with CT scan in a group of 110 UKA. In our study, the morphometric group has a significantly lesser external rotation of the tibial component than the symmetric group $(P=.04)$. We found the same conclusions as Iriberri and Aragon with better outcomes observed with lesser degrees of tibial external rotation, as excessive external rotation would result in a rotational incongruity between femur and tibia in extension.

The clinical comparison demonstrated that the patients of the MTT group had significantly better clinical outcomes in terms of global KSS, KOOS SF, and EQ5D3L and a better improvement in maximal flexion of the knee, pain and knee components of KSS and KOOS SF compared to the STT group. To our knowledge, no clinical study had studied before the clinical outcomes of this new design of implant in UKA. In our study, the KSS knee component improved from 52.4 to 85.1 and the KSS function component from to 72.6 to 94.0 for the STT group and for the MTT group, 49.8 to 91.2 and 70.0 to 97.3 for the KSS knee component and the KSS function component, respectively. Our results are in agreement with other studies using an STT: In the Kort et al's cohort of 46 patients (mean age, 56) who underwent UKA using the Oxford phase 3 implant, the KSS improved from preoperative 42.22 to 90.52 at the latest follow-up ( 2 years minimum, 6 years maximum) and the KSS function from 60 to 90.41 [1]. In the study of Gill and Nicolai [30], 452 medial Physica ZUK prostheses were implanted with a mean age of 67 and the KSS and the KSS function score improved significantly from 43.6 and 54.0 to 93.4 and 91.0, respectively. In our study, the clinical results of the STT group were comparable to the clinical results observed in studies using the same STT implants and the results of the MTT group were significantly higher $(P<.01)$.

Our subgroup analysis showed that the group of patients with no overhang had a higher maximal knee flexion. Chau et al [15] demonstrated that patients with significant medial overhang $>3 \mathrm{~mm}$ have an increased risk of worse knee and pain scores postoperatively at 5 years after surgery with a deterioration of the scores between 1 and 5 years. In our study, medial overhang $>3 \mathrm{~mm}$ was associated only with less improvement of maximal knee flexion between the preoperative and postoperative analysis at 1 year and consecutively lower values of knee flexion. This has important clinical implications: using this new design of tibial implant may reduce consequences of an inappropriate fit of the tibial implant such as pain, stiffness, and MCL tension [15]. An overhang $>3 \mathrm{~mm}$ may cause stiffness in the first year which might be later associated with pain and worst functional outcomes. It would be interesting to keep on following these patients and further evaluate the clinical outcomes of this subgroup.

\section{Conclusion}

The results of our study showed that the use of a morphometric tibial implant can improve the positioning of the tibial implant with a better tibial rotation, less medial and posterior overhang, and consequently better functional outcomes at 1-year follow-up after medial UKA. A longer follow-up is now required to know the longterm clinical benefits of a better implant positioning and to see whether there is also any associated impact on survivorship.

\section{References}

[1] Kort NP, van Raay JJ, van Horn JJ. The Oxford phase III unicompartmental knee replacement in patients less than 60 years of age. Knee Surg Sports Traumatol Arthrosc 2007;15:356-60. https://doi.org/10.1007/s00167-006-0204-9.

[2] Scott CEH, Wade FA, MacDonald D, Nutton RW. Ten-year survival and patientreported outcomes of a medial unicompartmental knee arthroplasty incorporating an all-polyethylene tibial component. Arch Orthop Trauma Surg 2018;138:719-29. https://doi.org/10.1007/s00402-018-2908-y.

[3] Campi S, Tibrewal S, Cuthbert R, Tibrewal SB. Unicompartmental knee replacement - current perspectives. J Clin Orthop Trauma 2018;9:17-23. https://doi.org/10.1016/j.jcot.2017.11.013.

[4] Parratte S, Ollivier M, Lunebourg A, Abdel MP, Argenson J-N. Long-term results of compartmental arthroplasties of the knee: long term results of partial knee arthroplasty. Bone Joint J 2015;97-B:9-15. https://doi.org/10.1302/0301$620 \times .97 B 10.36426$

[5] Cartier P, Sanouiller JL, Grelsamer RP. Unicompartmental knee arthroplasty surgery: 10-year minimum follow-up period. J Arthroplasty 1996;11:782-8.

[6] Capra SW, Fehring TK. Unicondylar arthroplasty. A survivorship analysis. J Arthroplasty 1992;7:247-51.

[7] Deshmukh RV, Scott RD. Unicompartmental knee arthroplasty: long-term results. Clin Orthop Relat Res 2001:272-8.

[8] Lyons MC, MacDonald SJ, Somerville LE, Naudie DD, McCalden RW. Unicompartmental versus total knee arthroplasty database analysis: is there a winner? Clin Orthop Relat Res 2012;470:84-90. https://doi.org/10.1007/ s11999-011-2144-z.

[9] Fabre-Aubrespy M, Ollivier M, Pesenti S, Parratte S, Argenson J-N. Unicompartmental knee arthroplasty in patients older than 75 results in better clinical outcomes and similar survivorship compared to total knee arthroplasty. A matched controlled study. J Arthroplasty 2016;31:2668-71. https:// doi.org/10.1016/j.arth.2016.06.034.

[10] Laurencin CT, Zelicof SB, Scott RD, Ewald FC. Unicompartmental versus total knee arthroplasty in the same patient. A comparative study. Clin Orthop 1991 $151-6$.

[11] Kaya Bicer E, Servien E, Lustig S, Demey G, Ait Si Selmi T, Neyret P. Sagittal flexion angle of the femoral component in unicompartmental knee arthroplasty: is it same for both medial and lateral UKAs? Knee Surg Sports Traumatol Arthrosc 2010;18:928-33. https://doi.org/10.1007/s00167-0101063-y.

[12] Kim JG, Kasat NS, Bae JH, Kim SJ, Oh SM, Lim HC. The radiological parameters correlated with the alignment of the femoral component after Oxford phase 3 unicompartmental knee replacement. J Bone Joint Surg Br 2012;94:1499-505. https://doi.org/10.1302/0301-620X.94B11.29217.

[13] Carpenter DP, Holmberg RR, Quartulli MJ, Barnes CL. Tibial plateau coverage in UKA: a comparison of patient specific and off-the-shelf implants. J Arthroplasty 2014;29:1694-8. https://doi.org/10.1016/j.arth.2014.03.026.

[14] Gudena R, Pilambaraei MA, Werle J, Shrive NG, Frank CB. A safe overhang limit for unicompartmental knee arthroplasties based on medial collateral ligament strains: an in vitro study. J Arthroplasty 2013;28:227-33. https://doi.org/ 10.1016/j.arth.2012.05.019.

[15] Chau R, Gulati A, Pandit H, Beard DJ, Price AJ, Dodd CAF, et al. Tibial component overhang following unicompartmental knee replacement-does it matter? Knee 2009;16:310-3. https://doi.org/10.1016/j.knee.2008.12.017.

[16] Bloebaum RD, Bachus KN, Mitchell W, Hoffman G, Hofmann AA. Analysis of the bone surface area in resected tibia. Implications in tibial component subsidence and fixation. Clin Orthop Relat Res 1994:2-10.

[17] Hofmann AA, Bachus KN, Wyatt RW. Effect of the tibial cut on subsidence following total knee arthroplasty. Clin Orthop Relat Res 1991:63-9.

[18] Stulberg SD, Goyal N. Which tibial tray design achieves maximum coverage and ideal rotation: anatomic, symmetric, or asymmetric? An MRI-based study. J Arthroplasty 2015;30:1839-41. https://doi.org/10.1016/j.arth. 2015.04.033.

[19] Fitzpatrick C, FitzPatrick D, Lee J, Auger D. Statistical design of unicompartmental tibial implants and comparison with current devices. Knee 2007;14:138-44. https://doi.org/10.1016/j.knee.2006.11.005.

[20] Wernecke GC, Harris IA, Houang MTW, Seeto BG, Chen DB, MacDessi SJ Comparison of tibial bone coverage of 6 knee prostheses: a magnetic resonance imaging study with controlled rotation. J Orthop Surg (Hong Kong) 2012;20:143-7. https://doi.org/10.1177/230949901202000201. 
[21] Argenson J-N, Chevrol-Benkeddache Y, Aubaniac J-M. Modern unicompartmental knee arthroplasty with cement: a three to ten-year follow-up study. J Bone Joint Surg Am 2002;84-A:2235-9.

[22] Servien E, Fary C, Lustig S, Demey G, Saffarini M, Chomel S, et al. Tibial component rotation assessment using CT scan in medial and lateral unicompartmental knee arthroplasty. Orthop Traumatol Surg Res 2011;97: 272-5. https://doi.org/10.1016/j.otsr.2010.11.002.

[23] Yoshioka Y, Siu DW, Scudamore RA, Cooke TDV. Tibial anatomy and functional axes. J Orthop Res 1989;7:132-7. https://doi.org/10.1002/jor.1100070118.

[24] Servien E, Saffarini M, Lustig S, Chomel S, Neyret P. Lateral versus medial tibial plateau: morphometric analysis and adaptability with current tibial component design. Knee Surg Sports Traumatol Arthrosc 2008;16:1141-5. https:// doi.org/10.1007/s00167-008-0620-0.

[25] Bizzozero P, Bulaid Y, Flecher X, Ollivier M, Parratte S, Argenson J-N. Morphometric tibial implant decreases posterior overhang rate and improves clinical outcomes: results of a prospective, matched controlled study. J Arthroplasty 2018;33:2804-9. https://doi.org/10.1016/j.arth.2018.04.020.
[26] Debette C, Parratte S, Maucort-Boulch D, Blanc G, Pauly V, Lustig S, et al. French adaptation of the new Knee Society Scoring System for total knee arthroplasty. Orthop Traumatol Surg Res 2014;100:531-4.

[27] Ornetti P, Perruccio AV, Roos EM, Lohmander LS, Davis AM, Maillefert JF. Psychometric properties of the French translation of the reduced KOOS and HOOS (KOOS-PS and HOOS-PS). Osteoarthritis Cartilage 2009;17:1604-8. https://doi.org/10.1016/j.joca.2009.06.007.

[28] Berliner JL, Brodke DJ, Chan V, SooHoo NF, Bozic KJ. Can preoperative patientreported outcome measures be used to predict meaningful improvement in function after TKA? Clin Orthop Relat Res 2017;475:149-57. https://doi.org/ 10.1007/s11999-016-4770-y.

[29] Iriberri I, Aragón JF. Alignment of the tibial component of the unicompartmental knee arthroplasty, assessed in the axial view by CT scan: does it influence the outcome? Knee 2014;21:1269-74. https://doi.org/10.1016/j.knee.2014.06.008.

[30] Gill JR, Nicolai P. Clinical results and 12-year survivorship of the Physica ZUK unicompartmental knee replacement. Knee 2019;26:750-8. https://doi.org/ 10.1016/j.knee.2019.02.016. 